\title{
EL SESGO DE GÉNERO EN LA POLÍTICA DE AUSTERIDAD DE ARGENTINA, 2015-2019. UNA MIRADA DESDE LA ECONOMÍA FEMINISTA
}

\author{
Patricia Laterra María Julia Eliosoff \\ $\frac{\text { patricialaterra@gmail.com }}{\text { Universidad de Buenos Aires y }} \frac{\text { mjeliosoff@gmail.com }}{\text { Universidad de La Plata }}$
}

Agostina Costantino

agoscostantino@gmail.com

Universidad Nacional del Sur

\section{RESUMEN}

El Gobierno que asume en Argentina en diciembre de 2015 configura un modo de desarrollo orientado a las finanzas y el extractivismo, la liberalización comercial y de capitales y las políticas de austeridad. Buscó disminuir el déficit fiscal y bajar los costos de producción nacionales para aumentar la competitividad intenacional. Se llevaron a cabo una serie de medidas que impactaron de manera diferencial y negativa sobre las mujeres y personas LGBT. La reforma previsional del año 2017, las dinámicas en el mundo del trabajo, los recortes presupuestarios en áreas sensibles al género y el cambio en la naturaleza de las políticas sociales son algunos de los ejemplos que analizamos en este trabajo. El objetivo es analizar la incidencia que este programa de austeridad tuvo con respecto a las mujeres y, en los casos en que se pueda analizar, a las personas LGBT.

Palabras clave: Argentina, género, política social, desarrollo, política.

THE GENDER BIAS IN ARGENTINA'S AUSTERITY POLICY, 2015-2019. A VIEW FROM THE FEMINIST ECONOMICS

\section{Abstract}

The government that took office in Argentina in December 2015 configures a mode of development oriented to finance and extractivism, trade and capital liberalization and austerity policies. It looked to reduce the fiscal deficit and lower national production costs in order to increase intenational competitiveness. So, a series of measures were carried out that negatively impacted on women and LGBT people. The pension reform of 2017, the dynamics in the world of work, budget cuts in gender-sensitive areas and the change in the nature of social policies are some of the examples that we analyze in this paper. The objective is to analyze the incidence that this austerity program had on women and, where it can be analyzed, on LGBT people in Argentina.

KEYwORDS: Argentina, gender, social policy, development, policy.

DOI: https://doi.org/10.25145/j.clepsydra.2021.20.01

Revista ClePSYDRA, 20; febrero 2021, pp. 9-37; ISSN: e-2530-8424 


\section{INTRODUCCIÓN}

Una lectura feminista de la economía es necesaria debido a que ninguna ciencia es neutral, como no lo es ningún conocimiento. En este sentido, el concepto de género es relevante porque es una categoría que nos revela una noción sobre relaciones sociales de poder, esto es, la desigualdad no es una cosa de mujeres y el género no es igual a mujeres. Estas relaciones de poder interactúan con otras -como las raciales, las étnicas, las etarias, las que componen los diferentes cuerpos con diferentes capacidades psíquicas, motrices-que implican dinámicas de discriminación y subordinación, creación de estadios de «normalidad» que devienen en estereotipos sociales. Incorporar la noción de género en el análisis económico nos ayuda a pensar cómo las relaciones de género, que estructuran relaciones sociales, tienen efectos concretos en las estructuras y las dinámicas no sólo sociales, sino también económicas.

Las últimas cuatro décadas en Argentina se caracterizaron por un modo de desarrollo basado en la explotación de "ventajas comparativas» y orientado a las exportaciones, con una participación cada vez menos importante de la autonomía respecto al mercado mundial dentro de los ejes principales de las políticas. Los distintos gobiernos que se sucedieron durante estos 40 años mantuvieron como eje estructural esta caracterización, pero con distintos matices que colorearon de diferentes maneras cada etapa dentro de este largo período. Tal es así que, luego de varios años de un neoliberalismo a ultranza durante los noventa, se pasó a partir del 2002 a una etapa neodesarrollista también orientada a la explotación de ventajas comparativas, pero con fuertes diferencias respecto a la naturaleza de las políticas sociales y la importancia del mercado interno como espacio relevante para la valorización del capital.

La llegada al Gobierno de una fuerza de derecha a fines del 2015 (llamada «Cambiemos») hace retomar el sendero previo (más típicamente neoliberal) configurando un modo de desarrollo orientado a las finanzas y el extractivismo, la liberalización comercial y de capitales y las políticas de austeridad. El mercado interno ya no resulta relevante para la acumulación de capital, por lo tanto se trata de disminuir el déficit fiscal a como dé lugar, y bajar los costos de producción nacionales para aumentar la competitividad internacional.

Como parte de esos objetivos, se llevaron a cabo una serie de medidas que impactaron diferencial y negativamente sobre las mujeres y las personas LGBT. La reforma previsional del 2017, los recortes presupuestarios en áreas sensibles al género, las dinámicas en el mundo del trabajo y el cambio en la naturaleza de las políticas sociales son algunos de los ejemplos que analizamos en este trabajo. El objetivo del mismo es analizar la incidencia que este programa de austeridad tuvo con respecto a las mujeres y, en los casos en que se pueda analizar, a las personas LGBT, en Argentina.

En el primer apartado de este trabajo caracterizamos la relación entre el desarrollo económico y el género, dando cuenta de que los programas de austeridad pueden formar parte de las estrategias de desarrollo de los países. Entonces no nos sería posible poder caracterizar etapas sin entender bajo qué modelos de desarrollo están insertas esas políticas. El objetivo de este apartado es enfatizar que las polí- 
ticas de austeridad no se diseñan ni se implementan en el vacío, sino que cumplen una función en la forma que toma el desarrollo económico en algunos países. En el segundo apartado nos proponemos analizar a través de la evidencia empírica disponible cómo han afectado los programas de austeridad en relación con el mercado de trabajo y otros determinantes de las condiciones de vulnerabilidad en mujeres y personas LGBT como las brechas de ingresos y los programas de transferencias condicionadas de ingresos. En el tercer apartado hacemos foco en los cambios de condicionantes para el acceso a políticas públicas significativas para las condiciones de vida como lo fue la reforma previsional y las políticas sociales de transferencias de ingresos. Asimismo, analizamos los recortes presupuestarios en áreas sensibles para las mujeres y personas LGBT. Por último, acercamos algunas conclusiones sobre la política de austeridad entre los años 2015-2019.

\section{Nota Metodológica}

Con respecto a los datos utilizados en el presente trabajo cabe aclarar que Argentina, como el resto de los países latinoamericanos, sigue conservando una matriz cis y heteronormada en sus estadísticas oficiales. Las agencias estadísticas consignan el sexo que se atribuye la persona que responde o inclusive el sexo consignado al nacer, con las opciones varón y mujer. No desconocemos que hay casos en los que la identidad de género es respetada si las personas se acomodan a las opciones. Ahora bien, las posibilidades continúan siendo varón y mujer. En ese sentido, creemos que los resultados de las estadísticas oficiales brindan un panorama cis heteronormativo de la información tanto por continuar con definiciones acotadas en torno a la identidad sexo genérica (y las personas teniéndose que «adaptar» a estas) como por la cantidad de casos no cis heterosexuales en el peso de la muestra. Respecto a las fuentes de información secundaria que dan cuenta de las realidades de personas LGBTQ, estas son escasas. En este sentido utilizamos informes de organizaciones no gubernamentales que en los últimos 10 años han realizado relevamientos específicos fundamentalmente sobre personas trans.

En conocimiento de tales informes, las referencias que realizamos en el presente trabajo a los efectos sobre las personas LGBTQ no son a través de las estadísticas oficiales, sino a través de las inferencias que, tanto en base a la teoría y a las experiencias como a los casos estudiados en otros países, pueden hacerse a partir del diseño e implementación de políticas públicas. Diversos estudios, específicos de la población trans, dan cuenta de la mayor vulnerabilidad en la que se encuentra este colectivo. En tanto conocimiento de la vulnerabilidad, es posible inferir que ciertas políticas contribuyen a profundizar situaciones de precariedad en la vida de estas personas. En ese sentido nos animamos a hacer algunos acercamientos a lo que creemos son -en grandes rasgos- las representaciones en algunos de estos temas de las personas LGBT. 


\section{DESDE DÓNDE HABLAMOS: MODO DE DESARROLLO Y GÉNERO}

Si hablamos de los programas de austeridad y sus impactos en términos de género, resulta crucial esclarecer una relación anterior y fundamental: la relación entre el desarrollo económico y el género. Los programas de austeridad forman parte de determinadas estrategias de desarrollo de los países, por ello es necesario entender la función de los roles sociales de género en las mismas. Como bien afirma Rodríguez Enríquez, la economía neoclásica (que domina el campo disciplinar de la Economía en la actualidad) no incluye como parte de sus análisis a las mujeres o a las relaciones de género, no hay tal distinción en el «individuo representativo». Esto no quiere decir que no incluyan análisis de impacto sobre las mujeres, tal como lo harían con cualquier otro grupo social definido por cualquier otro criterio (jóvenes, ancianos, pobres, etc.). En este sentido, la escuela neoclásica efectivamente analiza cuál es el impacto del desarrollo económico sobre las mujeres. Duflo afirma que el desarrollo económico, entendido simplemente como crecimiento del PIB, impactará positivamente sobre las mujeres a través de múltiples canales:

- El desarrollo económico produce una reducción de la pobreza. En este sentido, como las mujeres son las más afectadas por este "fenómeno», serán beneficiadas en una proporción mayor a los varones.

- El desarrollo económico produce una reducción de la cantidad de situaciones de discriminación niño-niña en las familias. Respecto a este punto se hace alusión a estudios (principalmente antropológicos) que muestran que las familias en situaciones extremas de vulnerabilidad y pobreza en determinados países (los estudios de caso suelen estar situados en India, Bangladesh, Pakistán) eligen cuidar a los niños por sobre las niñas (lo cual implica darles educación, salud, alimentación a unos y no a otras). Lo que afirma Duflo es que el desarrollo económico sacará a esas familias de la situación de extrema pobreza, lo cual reducirá las probabilidades de que tengan que elegir cuidar a los varones y no a las nińas.

- El desarrollo económico impacta positivamente sobre la autonomía de las mujeres a través de múltiples factores (desde la posibilidad de adquirir electrodomésticos hasta la baja de natalidad).

En definitiva, lo que afirma la escuela neoclásica es que el desarrollo económico impactará positivamente sobre las mujeres, aun sin la necesidad de que el desarrollo apunte a las mujeres. Es decir, no son necesarias las políticas de desarrollo con perspectiva de género o feministas porque el solo hecho de que exista desarrollo repercutirá sobre la equidad en este sentido.

Desde las posturas dominantes en Sociología también se analiza esta relación, y en el mismo sentido en que lo hace la escuela neoclásica en Economía: a mayor desarrollo, mayor inclusión de las mujeres. Desde la perspectiva del postmaterialismo de Inglehart se sostiene que cuando los países han alcanzado determinado nivel de desarrollo económico y tienen más seguridad en términos económicos, 
recién ahí empiezan a preocuparse por «valores postmaterialistas» (género, medio ambiente). Como ya no tienen que preocuparse por la supervivencia empiezan a valorar la autoexpresión (self-expression), la autonomía individual y los, llamados por esta perspectiva, «derechos de las minorías»". En este sentido, este cambio de valores se manifiesta en una mayor cantidad de derechos hacia las mujeres y la población LGBT en los países de más altos ingresos (Badgett $e t$ al.).

Ahora bien, ¿̇no es cierto que los países más desarrollados tienen más derechos relativos a las mujeres y las personas LGBT? Si se observan los datos, efectivamente se puede corroborar que, al menos los países más ricos de Occidente (Estados Unidos, Canadá, los países europeos), tienen legislados más derechos a favor de las mujeres y las personas LGBT que el promedio de los países latinoamericanos o africanos ${ }^{2}$. El problema de la escuela neoclásica y del postmaterialismo es otorgarle a esta relación empírica un estatus de causalidad ${ }^{3}$. El problema, entonces, es la interpretación teórica que se le da. En otra ocasión Costantino y Cantamutto han analizado la relación entre el desarrollo y el cumplimiento de determinados derechos humanos, y llegan a la conclusión de que el nivel de ingresos puede no ser la barrera para una mayor realización de derechos humanos socioeconómicos, ya que las modalidades bajo las cuales se busca aumentar esos ingresos no son neutrales. De la misma forma, en Costantino y Laterra se desarrolla la relación entre legislación sobre aborto y modos de desarrollo, encontrando que el grado de permisividad legal respecto a esta práctica puede estar relacionado con la función que cumplen los países en la acumulación mundial de capitales.

El cumplimiento de derechos (individuales y colectivos) no depende de cuánto crece un país (cuántos ingresos tiene), sino de cómo crece ese país, del «modo de desarrollo». De hecho, la forma en la que crece un país puede hacer que incluso cuando crezca el PIB empeoren las desigualdades de género. Los modos de desarrollo vigentes en América Latina afectan diferencial y negativamente a las mujeres y a las personas LGBT, y esto no tiene que ver con el nivel del PIB, sino con la forma que tiene ese PIB y, principalmente, con el rol cumplido por el país en la acumulación mundial de capitales. Un modo de desarrollo es la forma en la que se acumula y reproduce el capital en un momento y un lugar determinados. La forma que tenga esta acumulación repercute en la configuración de toda una serie de características de ese país no sólo en relación con la economía (salarios, nivel de empleo, cober-

${ }^{1}$ Discutimos conceptualizar estos avances de derechos para «minorías». No sólo porque en términos de cantidad no se trata de minorías, sino porque refiere a un estatus de minoridad, el cual le otorga una supuesta importancia menor frente a otras reivindicaciones.

2 Aquí pueden verse mapas sobre leyes de identidad de género: https://www.emol.com/noticias/Internacional/2018/01/31/893239/El-mapa-mundial-de-la-identidad-de-genero.html; matrimonio igualitario: https://www.bbc.com/mundo/noticias-internacional-40493968; e interrupción voluntaria del embarazo: https://actualidad.rt.com/actualidad/284358-mapa-estatus-legal-aborto-mundo.

${ }_{3}$ Para más referencias sobre la discusión entre las perspectivas neoclásica y postestructuralista del desarrollo en relación con el enfoque de la economía feminista ver Kabeer, Benería et al. y Floro. 
tura social), sino también en relación con la política (representación política, rol del Estado) y con lo social (sindicalización, conflictos sociales). En este sentido, el objetivo de este apartado es enfatizar que las políticas de austeridad no se diseñan ni se implementan en el vacío, sino que cumplen una función en la forma que toma el desarrollo económico en algunos países. No se trata simplemente de recortar gastos (ni cualquier gasto) porque sí. Se recortan gastos estratégicos que permiten, por un lado, abaratar costos para el capital (los que tienen que ver con seguridad social, derechos laborales, etc.) y, por otro lado, la transferencia de recursos hacia el exterior (por ejemplo, reorientando gastos hacia el pago de la deuda externa). Los procesos productivos intensivos en mano de obra barata y la transferencia de recursos hacia el exterior son dos características de los modos de desarrollo en países dependientes y periféricos como Argentina (Marini, Osorio, Féliz).

Desde fines de los setenta se inaugura un nuevo modo de desarrollo en Argentina, que replica con matices los mismos rasgos generales de toda América Latina. En el marco de las transformaciones mundiales que la crisis internacional de mediados de los setenta impulsó, desde los organismos multilaterales de créditos se exige en toda la región la aplicación de una serie de reformas estructurales como condición para el financiamiento y la entrada de capitales, en un contexto de reiteradas crisis de balanza de pagos que el proceso de sustitución de importaciones había implicado en Latinoamérica.

El resultado de la aplicación de estas reformas fue la integración al mercado mundial diluyendo las mediaciones nacionales. El interés del capital trasnacional (en América Latina en general, y en Argentina en particular) pasó a estar en el aprovechamiento de mano de obra barata y recursos naturales sin explotar con una orientación de la producción a las exportaciones (Osorio). Es decir, en los eslabones de extracción y producción de las cadenas globales de valor, dejando en países centrales las etapas que captan mayor valor, como el diseño, marketing, seguros, financiamiento, logística, etc.

En términos generales, el esquema anterior se mantiene en sus principales características desde aquel momento, pero va tomando matices con los distintos gobiernos. Durante el kirchnerismo ${ }^{4}$ se configuró un neodesarrollismo extractivista basado en la explotación de recursos naturales en manos de inversores extranjeros y un complejo sistema de redistribución de una parte de las rentas de este sector, por un lado, hacia la industria y, por otro (y en mucho menor medida), hacia políticas sociales. Este sistema generaba una serie de contradicciones que llegaron a su máxima tensión hacia finales del gobierno. Para ciertos sectores de la gran burguesía era crucial avanzar en la eliminación de las mismas.

Las políticas aplicadas por Cambiemos desde que asumió como Gobierno en diciembre del 2015 tuvieron como efecto retomar el sendero previo de profundización del esquema basado en la explotación de recursos naturales y la valoriza-

\footnotetext{
${ }^{4}$ Refiere a los gobiernos peronistas de Néstor Kirchner (2003-2007) y Cristina Fernández de Kirchner (2007-2015).
} 
ción financiera. Las posibles "contradicciones» existentes durante el kirchnerismo en torno al papel de la industria y la política social (más allá de los resultados) fueron barridas por una batería de políticas que invirtieron y profundizaron las posiciones generales de los ganadores y perdedores dentro de la estructura económica. Sintéticamente, puede decirse que el modo de desarrollo de Cambiemos se basó en cuatro grandes lineamientos:

- Profundización de la estructura extractivista de la producción (Vaca Muerta -potencial reserva de recursos hidrocarburíferos no convencionales-, disminución de retenciones al complejo agroexportador, eliminación del requerimiento de liquidar divisas por parte de los exportadores, etc.).

- Financierización de la estructura económica (endeudamiento, altas tasas de interés, y el mecanismo del carry trade o bicicleta financiera).

- Apertura y desregulación de las cuentas externas (eliminación del control de cambios, tratados bilaterales de inversión, eliminación de regulación de los movimientos de capitales).

- Políticas de austeridad (recortes en ciencia y tecnología, subejecución de partidas de gastos sociales y en salud, disminución real de salarios, jubilaciones y asignaciones sociales).

A pesar de que en este trabajo nos concentramos en el cuarto punto, podemos mencionar que los tres primeros también tienen impacto negativo en los cuerpos de las mujeres y personas LGBT. En el caso de la profundización del extractivismo, este proceso (ya iniciado desde el Gobierno anterior) trajo consigo la proliferación de conflictos socioambientales derivados de la forma e intensidad de la explotación de los recursos (Costantino y Gamallo). Como señalan las perspectivas ecofeministas, estos conflictos suelen estar protagonizados por mujeres, no porque estas tengan de manera innata una mayor conciencia ecológica (derivada de un instinto maternal), sino porque culturalmente el rol asignado a la mujer es el de cuidadora dentro de la economía familiar. La división sexual del trabajo y los estereotipos de género son, entonces, los que determinan la mayor conciencia ecológica de las mujeres y su mayor presencia en los conflictos ambientales.

En segundo lugar, la financierización de la estructura económica también impacta diferencialmente sobre las mujeres. A la par del endeudamiento público, en los últimos años creció exponencialmente el endeudamiento privado y, sobre todo, el endeudamiento de los sectores populares, a través de crédito público (a los beneficiarios de ANSES) ${ }^{5}$ o privado (las empresas financieras de microcréditos). Tal como afirman Cavallero y Gago, estos sectores populares ultraendeudados están

5 «En los últimos ańos ya se entregaron casi ocho millones de créditos ANSES, cuyos beneficiarios usaron el dinero para hacer refacciones en el hogar, afrontar gastos imprevistos o pagar deudas más caras»: https://www.infobae.com/economia/2019/04/17/en-el-primer-dia-la-anses-recibiomas-de-40-mil-solicitudes-para-la-nueva-linea-de-creditos/. 
altamente feminizados y entran en estos circuitos de endeudamiento para cubrir gastos de subsistencia y reproducción social que el Estado neoliberal dejó de proveer y que los montos de sus ingresos nos les permiten cubrir.

Tercero, la liberalización del comercio exterior. Esta liberalización implica, por una parte, un menor espacio fiscal posible para la realización de políticas sociales y públicas con perspectiva de género por la caída de ingresos debido a la apertura y la desregulación de las cuentas externas. Por otra parte, economistas feministas (Elson, Razavi, Fontana, Çağatay, entre otras) han propuesto variados enfoques y metodologías para analizar la existencia de los efectos diferenciados de la liberalización de la política comercial en las mujeres. La coerción de la política comercial y de inversiones por parte del poder corporativo y a través de captura corporativa del Estado propicia la reducción de costos laborales que afecta a todos/as los/as trabajadores/as y promueve a la baja las protecciones sociales en pos de incrementar el intercambio de determinados mercados para la obtención de mayores beneficios.

Por último, estos cuatro grandes lineamientos configuran un modo de desarrollo que está enfocado al mercado externo desestimando sobremanera el mercado interno y con ello provocando repercusiones negativas en el mundo de trabajo remunerado, con caída fuerte del salario real, flexibilización laboral y mayores mecanismos de precarización del trabajo remunerado. A saber, estos modos de desarrollo se complementan con regímenes de bienestar (Martínez Franzoni) que en las economías latinoamericanas se caracterizan por la provisión del bienestar y garantía de derechos en vínculo al mercado de trabajo. Si este mundo de trabajo remunerado en el cual las personas consiguen ingresos monetarios y protección social se ve afectado, quienes estén en mayor estado de vulnerabilidad insertos/as en el mundo del trabajo, como lo son las mujeres y las personas LGBT, se verán particular y negativamente afectadas/os por este cambio en la estrategia en el modo de desarrollo.

\section{CONDICIONES DE VIDA DE LAS MUJERES Y LAS PERSONAS LGBTIQ EN ARGENTINA}

Analizar las condiciones de vida desde la perspectiva de la Economía Feminista nos lleva a tres cuestiones. En primer lugar, incorporar la noción de género en el análisis económico nos ayuda a pensar estas relaciones de poder en relación con las cuestiones económicas que interactúan con otras -como las raciales, las étnicas, las etarias, las que componen los diferentes cuerpos con diferentes capacidades psíquicas, motrices- y que implican dinámicas de discriminación y subordinación, creación de estadios de «normalidad» que devienen en estereotipos sociales. En segundo lugar, poner en cuestión la definición y los límites del concepto de trabajo: este no es sólo aquel utilizado para la producción de bienes y servicios con valor económico en el mercado (la definición ortodoxa de trabajo en economía), sino también aquel necesario para la reproducción cotidiana de la vida. Una tercera cuestión, derivada de la anterior, es visibilizar el rol económico sistémico del trabajo doméstico y de cuidados en la reproducción cotidiana de la vida. 


\subsection{LA INTERRELACIÓN ENTRE LAS CONDICIONES DE VIDA Y LA ORGANIZACIÓN SOCIAL DEL TRABAJO}

No podríamos analizar las condiciones de vida de las personas desde la Economía Feminista sin tener en cuenta la organización social del cuidado (OSC) que da forma al sistema patriarcal actual de distribución sexual de los trabajos remunerados y no remunerados. La OSC refiere a la manera en que interrelacionadamente las familias, el Estado, el mercado y la comunidad producen y distribuyen cuidados (Rodríguez Enríquez y Pautassi), evidenciando e identificando los elementos y dimensiones que alimentan la reproducción de desigualdades. $\mathrm{La}$ OSC es un factor determinante en las manifestaciones de la desigualdad, ya que determina, entre otros factores, el tiempo disponible que queda para que las personas puedan participar del mundo del trabajo y otras necesidades. La evidencia recogida demuestra que la OSC en nuestras sociedades, y particularmente en los países de América Latina, es desigual e injusta (International Labour Organization y United Nations Development Programme; Rodríguez Enríquez; Lupica; Esquivel et al.).

Entonces, no podríamos caracterizar las condiciones de vida y los efectos de las políticas de austeridad sin dimensionar la esfera del uso diferenciado del tiempo y la configuración desequilibrada e injusta de la OSC. La última información disponible sobre trabajo no remunerado y uso del tiempo en Argentina, que refiere a los conglomerados urbanos en el año 2013 según un módulo adicional que se agregó a la Encuesta Permanente de Hogares del INDEC, muestra que las mujeres se involucran en un $88,9 \%$ en las tareas domésticas y de cuidado no remuneradas mientras que los varones se involucran en un $57,9 \%$. Adicionalmente, las mujeres destinan en promedio 6,4 horas diarias a estas actividades, mientras que los varones dedican casi la mitad, esto es, 3,4 horas. Esta información constata una cara de la desigualdad: la carga diferencial entre varones y mujeres es sustantiva dando cuenta de que estos trabajos se encuentran generizados y privatizados: se los piensa como una obligación de las mujeres y en el ámbito privado de los hogares. Sin embargo, es importante reconocer dos aspectos sobre su privatización. Por un lado, se encuentran los hogares que, contando con recursos económicos, compran trabajo de cuidado en el mercado, principalmente a otras mujeres que lo proveen, en la forma de servicios o en forma de productos. Por otro, muchos aspectos del cuidado se suplen derivando tales trabajos en las relaciones filiales (niñas, adolescentes, hermanas, hermanos, primas, madres, abuelas, tías) y/o en relaciones comunitarias. Otra de las caras es la desigual distribución entre hogares y el resto de los actores de la OSC. En este sentido, el mercado participa de manera muy segmentada, ya que sólo aquellos hogares que pueden comprar cuidado acceden a estos servicios. El Estado también participa de manera muy subsidiaria (Enríquez y Marzonetto), interviniendo en sectores muy específicos del cuidado como la educación o la salud para compensar aquellos hogares que por las razones que sean no consiguen atender sus necesidades de cuidado. La literatura al respecto define la injusta distribución del trabajo doméstico y de cuidados como un vector de reproducción de desigualdad (Enríquez y Marzonetto). 
Las dificultades de acceso en el mercado de trabajo, como la diferente participación, la brecha salarial y las dinámicas de segregación horizontal y vertical se asientan sobre esta distribución del tiempo desigual. La ausencia de políticas laborales, sumada a la recesión en la que se vio inmersa la economía argentina, se refleja en la profundización de las desigualdades de género estructurales del mundo de trabajo remunerado. Es por eso por lo que a partir de esta injusta organización social del cuidado analizamos las condiciones de vida de las mujeres cis, trans y travestis.

\subsection{LAS DINÁMICAS EN EL MERCADO DE TRABAJO}

La situación de las mujeres y personas LGBT en el mercado laboral es estructuralmente más precaria que la de los varones cis hetorosexuales. En general se observa que cuentan con menores tasas de actividad, mayores tasas de desempleo, mayor incidencia de la informalidad y mayor proporción de empleos de tiempo parcial. En coyunturas de crisis y recesión económica, como explicamos más arriba, estas desigualdades se profundizan debido a las propias configuraciones del modo de desarrollo y las características del régimen de bienestar.

A continuación, analizaremos algunos indicadores del mercado laboral que dan cuenta de las desigualdades del período 6 . Si bien las mujeres aumentaron su participación en los últimos 30 años, según las estadísticas oficiales, es notable que en lo que respecta a la tasa de actividad, la diferencia entre varones y mujeres continúa siendo muy significativa: las tasas de actividad de mujeres rondan alrededor de 20 puntos porcentuales por debajo de la de varones (como muestra el gráfico 1, alrededor del $44,1 \%$ y $64,7 \%$ en el 2016 , hasta $49,9 \%$ y $69,4 \%$ hacia finales del 2019 ). Es notorio que hacia fines del año 2018 y principio del 2019, momentos en que se profundiza la recesión, la tasa de actividad de las mujeres alcanza casi un $50 \%$. Este incremento de la tasa de actividad en las mujeres, aun en contextos de crisis económica, suele explicarse por las teorías del "trabajador adicional», donde las mujeres salen al mercado laboral a recomponer o sostener ingresos familiares (Águila).

En lo que respecta a las tasas de desempleo, en los últimos años se observan incrementos, sosteniéndose las brechas donde las mujeres presentan mayores tasas de desocupación que los varones. A lo largo de todo el período las brechas en las tasas de desempleo han variado entre 1,1 y 2,7 puntos porcentuales, dando cuenta de las dificultades del mercado para incorporar mujeres. Revisar estos datos teniendo en cuenta rangos etarios resulta aún más preocupante. Las brechas en las tasas de desempleo entre las personas jóvenes resultan en promedio 12,5 puntos porcentuales más altas que las del total. Cuando se observan por sexo, vemos que las mujeres jóvenes

${ }^{6}$ Los datos del 2015 no están disponibles, ya que durante ese año el Instituto de Estadísticas y Censos (INDEC) se encontraba en un proceso de revisión, evaluación de la Encuesta Permanente de Hogares (EPH) por cuestionamientos a la metodologías utilizadas en la encuesta. https:// www.indec.gob.ar/ftp/cuadros/sociedad/anexo_informe_eph_23_08_16.pdf. 


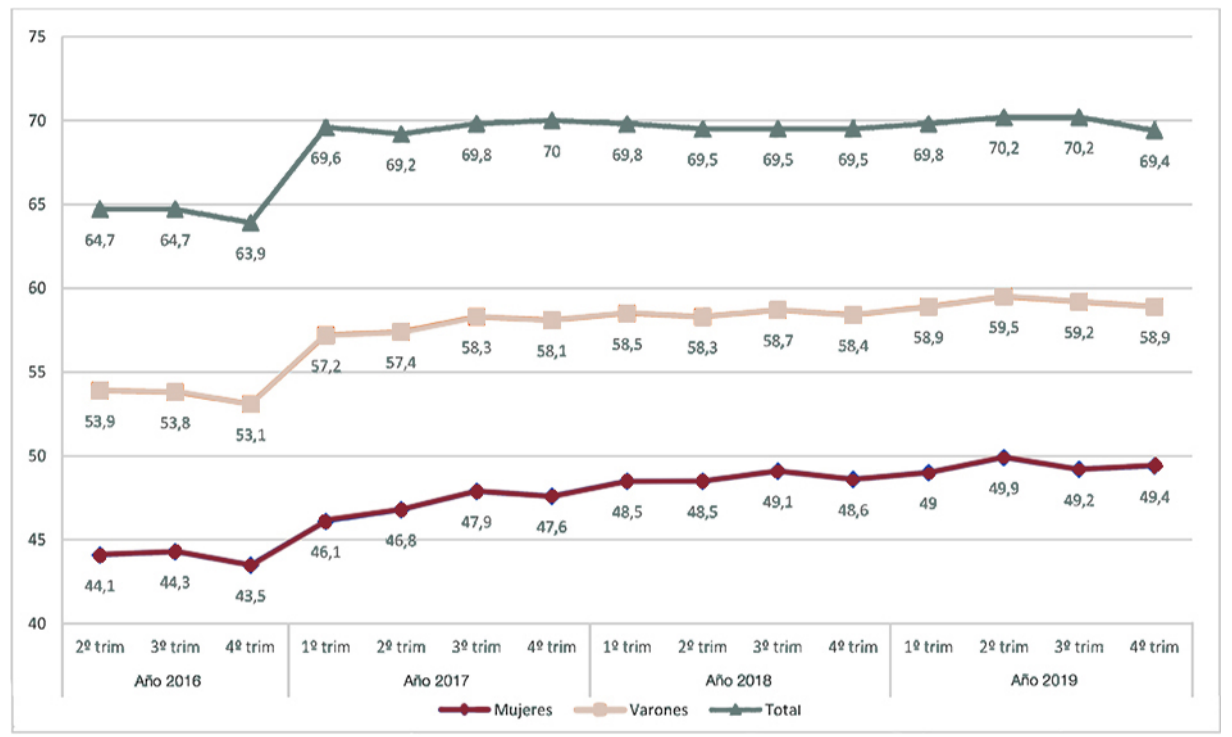

Fuente: elaboración propia en base a EPH-INDEC.

Gráfico 1. Tasa de actividad según sexo y población total. 31 aglomerados urbanos.

han tenido tasas de desempleo en promedio 14 puntos porcentuales más que sus congéneres de mayor edad. Esta situación, junto con las bajas tasas de actividad de las mujeres, da cuenta del fenómeno conocido como jóvenes «nini»" en su mayoría mujeres jóvenes, que no están insertas en el mercado laboral y tampoco se encuentran estudiando dado que se ocupan de sostener en sus hogares el trabajo doméstico y de cuidados no remunerado. Para los varones jóvenes, la situación se repite, pero con datos menos agobiantes: las brechas en las tasas de desempleo entre jóvenes y adultos alcanzan los 10 puntos porcentuales, y en promedio 6 puntos porcentuales con los datos totales. Revisar indicadores del mercado laboral desagregados por rangos etarios permite incluir una mirada interseccional donde se observa con claridad que la inserción laboral de lxs jóvenes es una problemática grave que se asocia a la informalidad y factores de precariedad laboral.

Con respecto a las personas trans ${ }^{8}$, un informe de la Fundación Huésped y la Asociación de Travestis, Transexuales y Transgéneros de la Argentina (ATTA) en

7 El 95\% de las personas jóvenes nini son mujeres que cuidan: https://www.cippec.org/ textual/los-mal-llamados-jovenes-nini-son-chicos-y-chicas-que-no-estudian-porque-cuidan-67-el95-son-mujeres/.

${ }^{8}$ No existen estadísticas oficiales que den cuenta de la situación de empleo de las personas trans, travestis, transexuales, no binaries, como tampoco para personas lesbianas, gais, bisexua- 


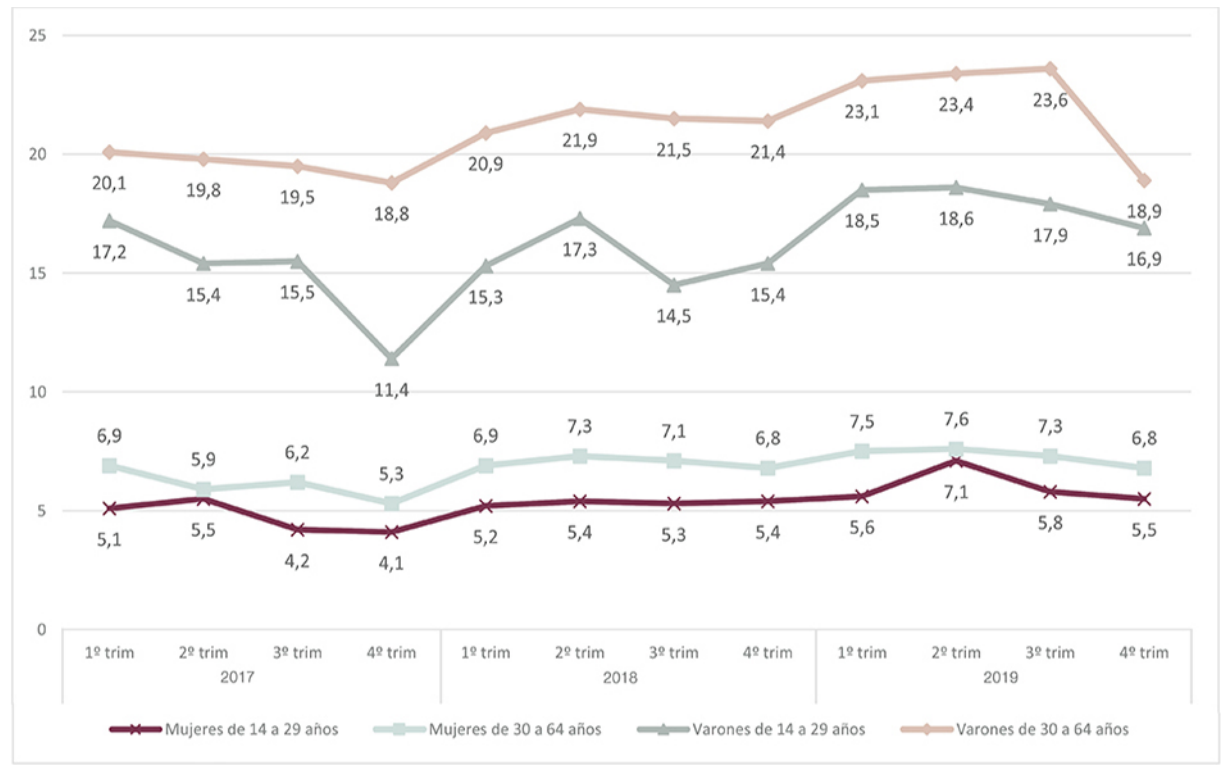

Fuente: elaboración propia en base a EPH-INDEC. (1) Datos provisorios.

Gráfico 2. Tasa de desempleo según rangos etarios y sexo. 31 aglomerados urbanos.

el 2014 muestra que sólo el 18\% de las personas travestis y trans de su estudio tiene acceso al trabajo remunerado en relación de dependencia y/o en relación con un empleador, constatando que tan sólo el 9,8\% de las personas aporta al sistema previsional argentino (SIPA). Si bien el $83,8 \%$ de la muestra revela que las personas trans tiene algún tipo de trabajo, un $70,7 \%$ dice trabajar por cuenta propia o de manera autónoma y un $5 \%$ en trabajo familiar sin remuneración. Los datos del informe evidenciaron una situación laboral precaria de elevada inseguridad e informalidad que continúa. Asimismo, sólo 14,6\% mencionó nunca haber realizado trabajo sexual, las restantes, 6 de cada 10 participantes estuvieron o estaban vinculadas al trabajo sexual. El estigma y la discriminación asociados a la identidad de género en el ámbito laboral es uno de los factores amenazantes para la plena participación en el mercado de trabajo en conjunto con la falta de oportunidades. El 41,6\% de las personas mencionaron haber sentido rechazo o vivido situaciones de discriminación y el $25 \%$ mencionó ser discriminada por jefes y compañeras/os de trabajo.

les. Desde el organismo oficial INDEC sólo existe un informe del año 2012 elaborado con INADI: «Primera encuesta sobre Población Trans 2012: travestis, transexuales, transgéneros y hombres trans. Informe técnico de la Prueba Piloto Municipio de La Matanza». 


\subsection{Otros DETERMINANTES DE LAS CONDICIONES DE VULNERABILIDAD EN MUJERES Y PERSONAS LGBT}

\subsubsection{Brechas de ingresos}

Con respecto a la brecha de ingresos de ocupados/as el centro CEPA estimaba ${ }^{9}$ que para el segundo trimestre del 2015 era del $22 \%$ y la brecha de ingresos personales del $26 \%$. En el tercer trimestre del $2019^{10}$, la DNEIyG estimó que la brecha de ingresos de ocupados/as alcanzó un $26,1 \%$ y la brecha de ingresos personales un $29 \%$. En el 2015, el $10 \%$ más pobre de la población recibía el 1,5\% del ingreso total. Este porcentaje se mantiene igual en el 2020. Ahora bien, el 10\% más rico de la población, en el 2015 recibía el 25,9\% de los ingresos y en el 2019 recibe el $31 \%$ de los ingresos. En efecto, en referencia a los datos de distribución del

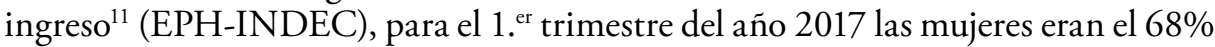
del decil de más bajos ingresos, donde el 63,2\% de esos ingresos son no laborables. En el decil de ingresos más altos, el $37 \%$ son mujeres. Hacia el segundo cuarto del año 2019, las mujeres en el decil más bajo eran el $69 \%$ y el $55,1 \%$ de sus ingresos no provenían de un ingreso laboral. La representación de mujeres en el decil de más altos ingresos cayó a 36\%. Esto quiere decir que en estos cinco ańos la desigualdad aumentó. Esta diferencia en los ingresos, sumada a las mayores dificultades de las mujeres cis, las personas trans y aquellas que no se ajustan a la heteronorma para acceder a empleos y beneficios de la protección social, y en términos más amplios para acceder y controlar recursos económicos, explica el evidente proceso sostenido de empobrecimiento. Asimismo, el $27 \%$ de los hogares argentinos son monoparentales y, de estos, el $84 \%$ tiene jefatura femenina. El mayor porcentaje de hogares monoparentales se da entre los deciles de menores ingresos; dentro de este universo, el 66\% de los hogares tiene un ingreso por debajo de la línea de pobreza y el $60 \%$ de estos tienen jefatura femenina (Scarano et al.). Con respecto a las políticas sociales para paliar la pobreza, según la Encuesta Nacional sobre Estructura Social, el 47\% de los hogares monoparentales encabezados por mujeres perciben la Asignación Universal por Hijo (AUH) como ingreso principal, en relación con los otros tipos de hogar, ubicando un lugar preponderante de esta política en la economía de las mujeres. Estos datos evidencian sólo una parte de la pobreza, es decir, la que otorga una perspectiva acerca de lo que no se puede obtener debido a la falta de ingresos. Sin embargo, la Economía Feminista discute estos indicadores en tanto analizan únicamente factores vinculados a los ingresos. En particular se discute lo acotado de estos indicadores, ya que los hogares monoparentales no tienen las mismas necesidades, arreglos económicos y de tiempo que los que pueden tener una familia tipo,

${ }^{9}$ Fuente de datos: https://centrocepa.com.ar/informes/43-mas-precarizadas-y-con-menores-salarios-la-situacion-economica-de-las-mujeres-argentinas.

${ }^{10}$ Fuente de datos: https://www.argentina.gob.ar/sites/default/files/las_brechas_de_ genero_en_la_argentina_0.pdf.

${ }^{11}$ En el caso de la serie distribución del ingreso para el año 2015 no hay informes desagregados por sexo. No es hasta el 2017 cuando pueden visualizarse de esa manera. 
así como incorporando otros factores de incidencia de pobreza como lo es el peso del trabajo doméstico y de cuidados no remunerado en la pobreza de tiempo. Estos estudios hacen referencia a la pobreza oculta.

\subsubsection{Deterioro de los ingresos en los programas de transferencias condicionadas}

Por último, para terminar de analizar la profundización de la precariedad en las condiciones de vida de las mujeres, es necesario dedicar un apartado a la pérdida de poder adquisitivo de tres programas de transferencias condicionadas de ingreso centrales del período.

En primer lugar, la Asignación Universal por Hijo (AUH) es una prestación no contributiva implementada en el 2009, destinada a niñas, niños y adolescentes menores de 18 años, hijos/as de trabajadores en el sector informal o desempleados. El 90\% de las que lo perciben son mujeres (CIPPEC). Esta política incluye condicionalidades en educación y salud que son llevadas adelante mayoritariamente por mujeres. Tal como se muestra en el gráfico 3, entre los ańos 2015 y 2019 la AUH percibió un aumento nominal del $228 \%$, mientras que en términos reales significó una caída del $16 \%$. Por otro lado, poniendo en relación el monto de la AUH con los costos de cubrir necesidades alimentarias de niños, niñas y adolescentes, el 90\% de estos no pueden garantizarse a través de esa prestación (CEPA). El informe de CEPA advierte que si se analiza el poder de compra de la Asignación Universal por Hijo (AUH) en términos de la Canasta Básica Alimentaria por adulto equivalente, surge que no alcanza para cubrir los requerimientos mínimos de los niños, niñas y adolescentes a partir de los dos años. Lo que se percibe mensualmente de la AUH sólo supera la canasta para los casos de niños de 0 y un años y en el caso de adolescentes de 17 ańos sólo cubre del $41 \%$ al 55\% de la misma (CEPA).

Un segundo ingreso significativo para las mujeres y las personas trans son los provenientes de los programas Argentina Trabaja y Ellas Hacen, y a partir del 2018 Hacemos Futuro ${ }^{12}$. Aunque no existen datos desagregados sobre percepción de estas transferencias de ingresos, por diversos medios podemos constatar que las personas trans son perceptoras de estos programas, aunque estén enfocados en mujeres ${ }^{13}$. Del análisis de los montos de estos programas - gráfico 4- se observa que a lo largo del período aumentaron en términos nominales un $227 \% \mathrm{y}$, sin embargo, debido al

12 En el próximo apartado se describen estos programas y el cambio de perspectiva de estos programas y de la política social en general.

${ }_{13}$ El programa «Ellas Hacen» ya incorporó a 300 mujeres trans y a fin de año serán casi 600 las beneficiarias. https://www.telam.com.ar/notas/201710/209958-programa-ellas-hacen-trans-trabajo-empleo-beneficios-formacion.html. Ellas Hacen incluye a las mujeres trans. https://www.eltribuno.com/salta/nota/2018-1-17-0-0-0-ellas-hacen-incluye-a-las-mujeres-trans. http://www.inadi.gob. ar/2017/09/25/mujeres-trans-beneficiarias-del-programa-ellas-hacen/. Programa Hacemos Futuro: la comunidad trans destacó cambios en su calidad de vida. https://www.mendoza.gov.ar/prensa/programa-hacemos-futuro-la-comunidad-trans-destaco-cambios-en-su-calidad-de-vida/. 


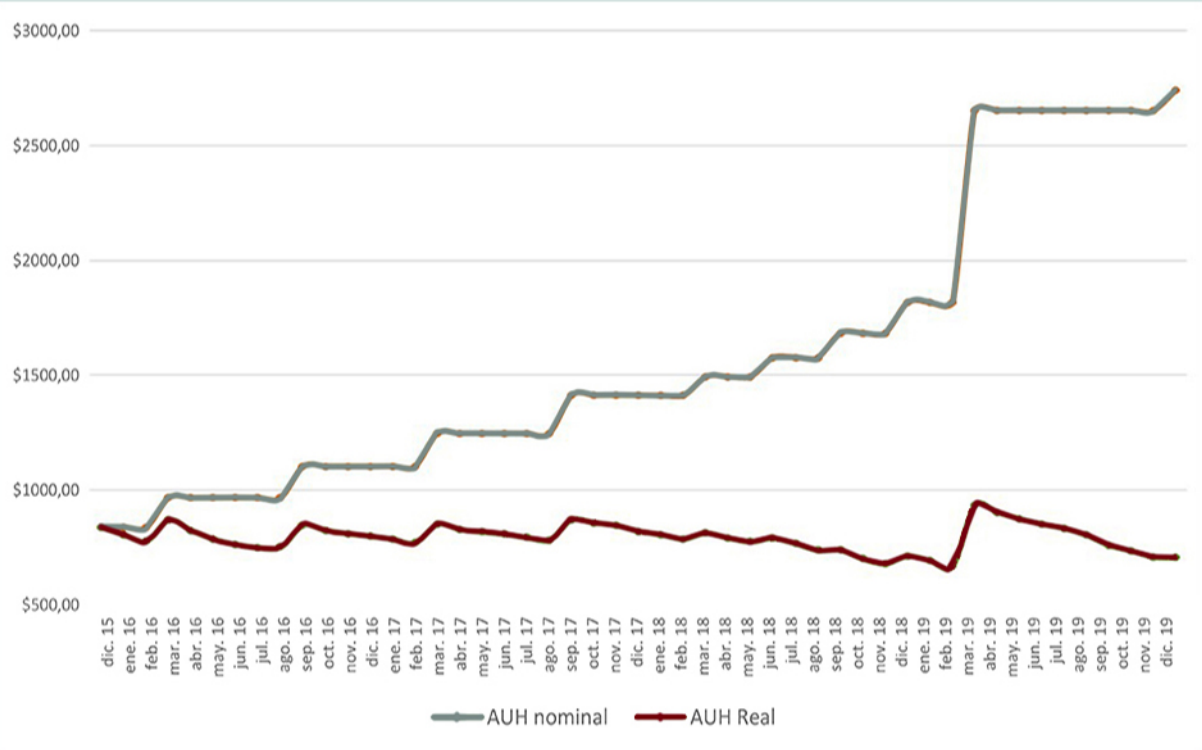

Fuente: elaboración propia en base a datos del Observatorio de Coyuntura Económica y Políticas Públicas (OCEPP).

Gráfico 3. Asignación Universal por Hijo: evolución de los ingresos nominales y reales a precios de diciembre del 2015 .

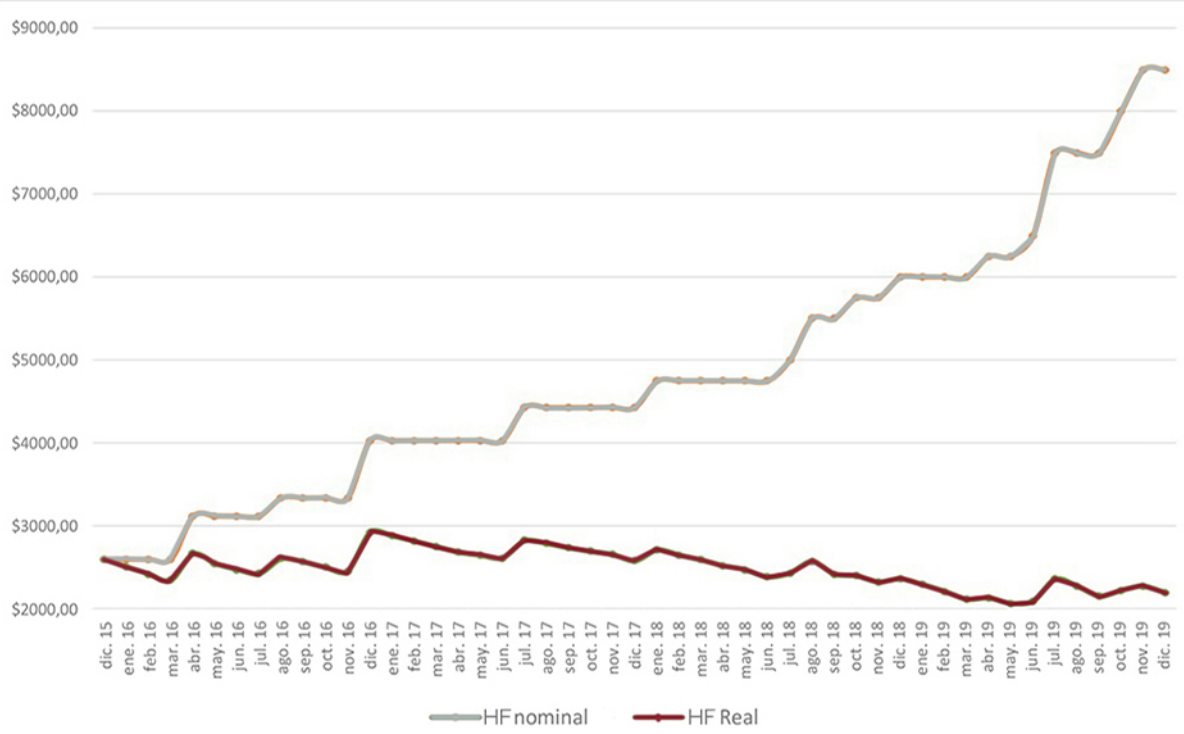

Fuente: elaboración propia en base a datos del Observatorio de Coyuntura Económica y Políticas Públicas (OCEPP).

Gráfico 4. Argentina Trabaja, Ellas Hacen y Hacemos Futuro: evolución de los ingresos nominales y reales a precios de diciembre del 2015. 


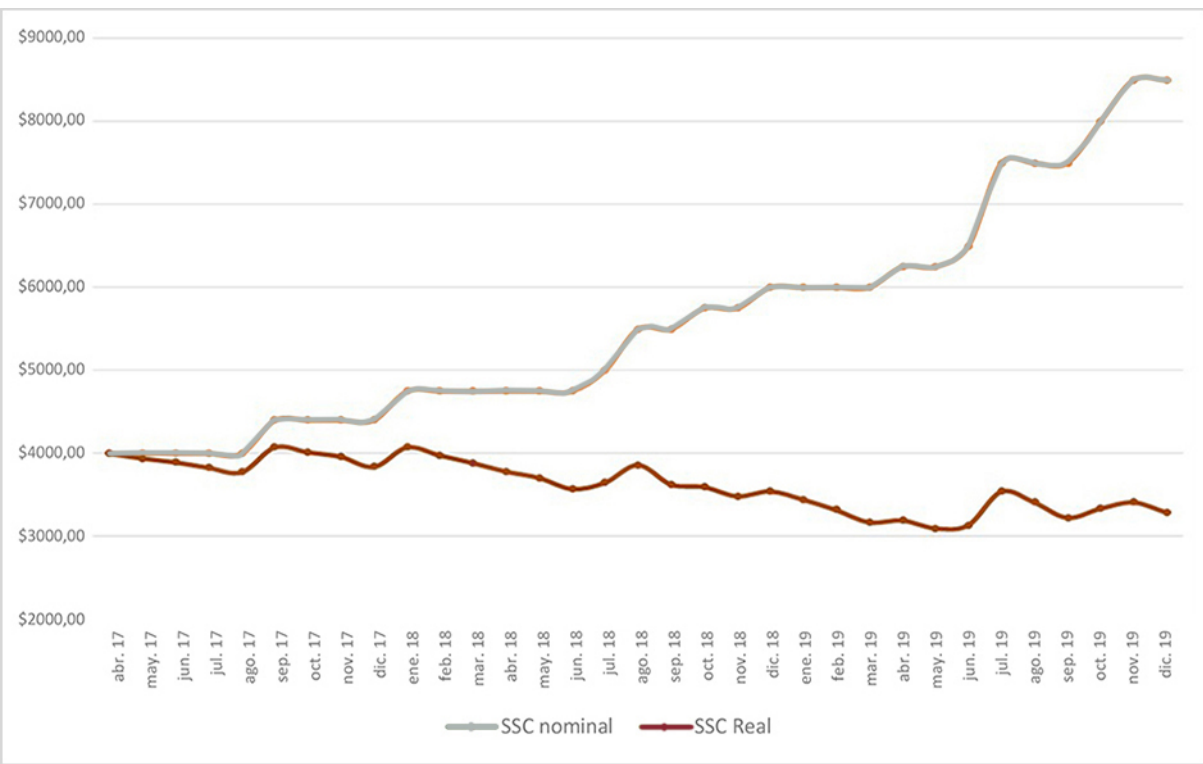

Fuente: elaboración propia en base a datos del Observatorio de Coyuntura Económica y Políticas Públicas (OCEPP).

Gráfico 5. Salario Social Complementario: evolución de los ingresos nominales y reales a precios de abril del 2017.

proceso inflacionario en el que se sumergió el país, especialmente desde mediados del 2018, los ingresos reales cayeron un 16\% en términos reales. Estos programas no superan la inflación real interanual para los últimos dos años de análisis.

Por último, se menciona lo ocurrido con la pérdida del poder adquisitivo del Salario Social Complementario, subsidio implementado por el Gobierno de Cambiemos en el marco de una lucha de los movimientos sociales por la Emergencia Social ${ }^{14}$. Desde su implementación en abril del 2017 el Salario percibió una pérdida de poder adquisitivo del 19\%, a pesar de un aumento nominal del $113 \%$, esto puede verse en el gráfico 5.

Este apartado nos permite contar con información para reconocer la profundización de la precariedad de la vida en términos de ingresos. Ya sea por las desigualdades en el mercado de trabajo y las mayores dificultades para las mujeres de contar con un ingreso, debido al incremento en las desigualdades entre deciles o la pérdida de poder adquisitivo de los ingresos de los sectores más vulnerados, donde las mujeres aparecen sobrerrepresentadas.

14 También se desarrolla en el próximo apartado 


\section{INCIDENCIA DE LOS PROGRAMAS DE AUSTERIDAD Y AJUSTE FISCAL EN EL MODO DE DESARROLLO}

En sociedades desiguales, las políticas públicas implementadas desde el Estado son claves para reducir las brechas de desigualdad producto de los modelos de desarrollo, aunque también pueden contribuir a perpetuarlas o profundizarlas. La aplicación de las políticas públicas es resultado de la puja y presión que los distintos grupos de interés ejercen sobre el Gobierno y que, sin embargo, a pesar de estas pujas, como explicaba Poulantzas, el mismo siempre conserva un cierto grado de autonomía, que le permite administrar distintos tipos de concesiones a los actores perdedores (Costantino). Dentro de la economía mundial en crisis, Argentina se encuentra en el grupo de países que viene proponiendo y ejecutando activamente la nueva oleada de reformas de ajuste estructural, programas de austeridad y restricción fiscal. Sin embargo, diferentes analistas ya han comprobado las enormes repercusiones negativas $^{15}$ que estas reformas contienen para las personas en situación de vulnerabilidad, en una clara restricción de acceso a derechos y garantías de sus derechos humanos. En especial, si incorporamos la perspectiva de género para analizar estas políticas y teniendo en cuenta lo analizado en el apartado 2 sobre condiciones de vida de las mujeres, lo que la evidencia muestra es que los programas de austeridad repercuten más en las mujeres y las personas LGBT porque son quienes se encuentran sobrerrepresentadxs en las zonas de la precariedad del mercado laboral, la protección social, el tiempo disponible y la política social (Laterra et al.).

\subsection{REFORMA PREVISIONAL}

Parte del objetivo impuesto por el Gobierno de Cambiemos fue el aumento de la competitividad internacional vía la disminución de costos. Uno de los costos que se buscó bajar durante todo el mandato fue el costo laboral. No sólo los salarios, que, en efecto, disminuyeron en términos reales a lo largo de los cuatro años de referencia, sino también todos los otros costos asociados a la contratación de trabajadoras y trabajadores. Entre ellos, los costos de la seguridad social. En la antesala de la reforma previsional en julio del 2016, el Gobierno decidió junto con la Ley de reparación histórica, que instauraba el $82 \%$ móvil, dar de baja una serie de leyes en torno a las moratorias previsionales e instaurar la Pensión Única para el Adulto Mayor (PUAM). Presentada como medida progresiva, significó el empeoramiento de las condiciones de vida de adultxs mayores por la pérdida en el cálculo de los reajustes de los haberes y el desconocimiento del derecho a decidir sobre los reajustes de los

${ }^{15} \mathrm{Al}$ respecto consultar el informe «La economía del primer año de Cambiemos», FES, http://library.fes.de/pdf-files/bueros/argentinien/13397.pdf; «La economía argentina a dos años de gobierno de Cambiemos»: https://library.fes.de/pdf-files/bueros/argentinien/14511.pdf. Barrera Insua, Facundo: http://revistamestiza.unaj.edu.ar/la-cuenta-william-boo/. 
mismos. Al mismo tiempo, esta ley puso fin a una serie de moratorias que, aunque no incluyeran explícitamente dentro de su redacción ninguna referencia a las mujeres sino únicamente a los "trabajadores autónomos» o «asalariados que no cumplieran con los requisitos de aportes», desde su creación concedió un valor simbólico a las trayectorias de vida de las personas que históricamente trabajaron de manera precaria e interrumpida y en especial a las mujeres, siendo una herramienta para que en la adultez mayor pudieran conseguir un haber previsional. Debido a la presión social la ley no fue aprobada con los cambios de máxima que esperaba el Gobierno. Sin embargo, fue fuertemente perjudicial para las mujeres, y personas trans, sobre todo aquellas que pertenecen a los estratos más bajos de la sociedad, quienes han tenido trayectorias informales y precarias. Como la fórmula de actualización de las jubilaciones es la misma que para las asignaciones de la seguridad social, también disminuyeron fuertemente en términos reales los montos de la Asignación Universal por Hijo y de las pensiones no contributivas. Algunos datos cuantitativos para tener en cuenta el alto impacto que tuvo estas reformas en las condiciones de vida de las mujeres muestran que:

- Al 2019, el 63\% de las personas jubiladas y pensionadas en Argentina son mujeres ${ }^{16}$. - Al 2015, el $79 \%{ }^{17}$ de las personas que entraron en la moratoria previsional son mujeres. Y, justamente, el motivo de la insuficiencia de aportes a lo largo de su vida responde al haber dedicado su vida a tareas de cuidados no remuneradas, o a tareas remuneradas, pero de manera interrumpida, insuficiente e informal.

- Al 2015, el 75,1\% de las personas beneficiarias de pensiones no contributivas (por vejez, por invalidez o para madres de siete hijos) son mujeres ${ }^{18}$.

- Al 2019 y como constante en los cuatro años el $95 \%{ }^{19}$ de las personas titulares responsables que cobran $\mathrm{AUH}$ son mujeres.

Esta reforma impactó directamente sobre la calidad de vida de las mujeres por distintas vías (Laterra et al.. ${ }^{20}$. En primer lugar, deterioró el nivel monetario de las prestaciones previsionales y asignaciones sociales por el cambio en el método de cálculo que afecta a los haberes previsionales y las transferencias monetarias y dismi-

${ }^{16}$ https://www.anses.gob.ar/informacion/datos-abiertos-pasivos. No existen datos desagregados entre personas cis y trans.

${ }_{17}$ Fuente ENAPROSS: http://observatorio.anses.gob.ar/archivos/documentos/DT_1601_ Cobertura\%20Previsional.pdf.

${ }_{18}$ Fuente ENAPROSS: http://observatorio.anses.gob.ar/archivos/documentos/DT_1601_ Cobertura\%20Previsional.pdf.

${ }_{19}$ Observatorio ANSES: http://observatorio.anses.gob.ar/archivos/publicaciones/Boletin\%20mensual\%20AUH\%20Mayo\%202019.pdf.

${ }^{20}$ Un informe detallado del impacto de la reforma puede verse en Laterra, Partenio, Rodríguez Enríquez y Ape (2018): "Las políticas de "austeridad” en la Argentina y su impacto diferenciado en las mujeres, travestis y personas trans». CELS: https://www.cels.org.ar/web/wp-content/ uploads/2018/04/20180405_Impacto_politicas_economicas_mujeres-2.pdf. 
nuye el potencial aumento de los beneficios sociales. Por ejemplo, en marzo del 2018 en lugar de otorgarse el aumento semestral del período anterior, que rondaba en un $12 \%$, se otorgó un aumento que bajo la nueva fórmula arrojaba un $5,7 \%$ de aumento. En segundo lugar, el proceso de reformas excluyó a trabajadoras/es informales o precarizada/os. A través de la firma de la Ley de reparación histórica y con la instauración de la PUAM se dieron de baja las distintas moratorias previsionales por las cuales muchísimas mujeres (así como también personas LGBT) ${ }^{21}$ se incorporaron al sistema previsional debido a que no habían acumulado los registros contributivos suficientes por sus trayectorias laborales intermitentes e informales. En el caso de las mujeres son muy comunes las salidas y entradas al mundo del trabajo remunerado por las cargas de cuidado o por haber cuidado durante toda su vida. Esta decisión, revertida temporalmente tres años después de su sanción (cerca de su fin), luego de una intensa movilización del movimiento de mujeres y feminista, consiguió extender el plazo para las moratorias hasta el 2022 pero sin una solución de raíz para las trayectorias de vida de las personas con alta informalidad en el mercado de trabajo y cargas de trabajos de cuidados. Por otro lado, la instauración de la PUAM, a la vez que desincentiva la aplicación a la moratoria (ya que se deben constatar registros contributivos y pagar en retroactivo 60 cuotas de lo no aportado), aumenta la edad necesaria para poder percibir el beneficio y crea una diferenciación entre quienes pudieron ingresar registros contributivos y quienes no. Entre los perjuicios se pueden constatar el aumento de la edad a partir de la cual se percibe el beneficio (de 60 a 65 años); la disminución del monto con respecto al haber mínimo previsional (80\%), creando una discriminación entre quienes pudieron contribuir en su historia laboral y quienes no; y la incompatibilidad con la percepción de otro beneficio social, únicamente pudiendo ser compatible con la AUH, ya que, en caso de tener derecho a obtener pensión por viudez, la persona debe elegir o renunciar a la percepción de este beneficio. En los hechos se violan los principios de igualdad y no discriminación ya que se termina creando en la práctica dos haberes mínimos para la población adulta mayor. Un mínimo para los que completaron 30 ańos de servicios con aportes efectivos y otro mínimo para quienes históricamente el mercado laboral y la división sexual del trabajo los ha precarizado de diferentes formas, haciendo esta práctica continua en la adultez mayor.

\subsection{CARACTERIZACIÓN DEL CAMBIO DE PERSPECTIVA DE LA POLÍTICA SOCIAL}

Durante los gobiernos kirchneristas (2003-2015), la política social se orientó a través del trabajo a mejorar las condiciones de vida de los sectores populares. Esa ampliación de los horizontes laborales se realizó a través del fomento de, en un

${ }^{21}$ Todavía no existen registros desagregados sobre la percepción de personas LGBT a la PUAM, pero, dado que estas personas han tenido registros contributivos insuficientes debido a la informalidad e interrupción en el mercado formal de trabajo, esta pensión hace posible el acceso a un haber previsional en la edad pasiva. 
primer momento, el trabajo asociativo (en pequeños grupos) a través de programas como "Manos a la Obra", que consistía en otorgar un subsidio en bienes de capital e insumos para crear o fortalecer un emprendimiento productivo. Esta estrategia se acompañó fuertemente con la promoción del microcrédito ${ }^{22}$. Luego, la política social se reconfiguró al Programa de Ingreso Social con Trabajo (PRIST), cuya principal línea fue el "Argentina Trabaja», que, a diferencia de los programas tradicionales de transferencias condicionadas de ingreso, proponía una retribución a través de la incorporación a cooperativas de trabajo. A través de estas cooperativas se realizaron obras de baja complejidad, mantenimiento de espacios verdes y obras de mejoramiento barrial, así como capacitaciones en oficios y terminalidad educativa.

Desde el año 2013 el programa incorpora la línea «Ellas Hacen». Orientada específicamente a mujeres y personas trans en situación de vulnerabilidad o violencia de género, logró mejorar las condiciones de vida de muchas mujeres y personas trans. Se promovió la formación en oficios tradicionalmente no feminizados (herrería, albañilería, carpintería), la finalización educativa obligatoria, la formación en género a través de diplomaturas y tecnicaturas dictadas por Universidades Nacionales, pero especialmente el fortalecimiento de lazos comunitarios entre mujeres. Estos lazos permitieron la organización en los barrios, el sostenimiento de los proyectos tanto desde sus estrategias productivas como comerciales, la continuidad en el estudio y sobre todo el sostén económico y emocional de ellas mismas.

Con la asunción del Gobierno de Cambiemos, las líneas del PRIST comienzan a modificarse ${ }^{23}$ (Hopp) enfatizando su carácter de formación para la empleabilidad. En diciembre del 2017 se sanciona por ley la Emergencia Social (Ley 27 345) impulsada fuertemente por organizaciones sociales, en particular la Confederación de Trabajadores de la Economía Popular (CTEP) que nuclea gran diversidad de organizaciones sociales. Esta ley profundiza la transformación de la política social llevada a cabo hasta el momento respecto a las situaciones de vulnerabilidad social. La Ley da surgimiento al Salario Social Complementario (SSC), una transferencia monetaria individual cuyo objetivo es completar los ingresos de los/as trabajadores/ as de la Economía Popular, para equipararlo al de un trabajador asalariado formal. Si bien significó una conquista para las organizaciones, el proyecto finalmente aprobado sufrió grandes modificaciones de la propuesta original presentada por las organizaciones que planteaban continuidad en las políticas en clave asociativa (Hopp).

Como última clave en este proceso de transformación de la política social del Gobierno de Cambiemos, en febrero del 2018 las líneas «Ellas Hacen», «Argentina Trabaja» $\mathrm{y}$ "Desde el Barrio» fueron unificadas en un nuevo programa llamado «Hacemos Futuro» (RESOL-2018-151-APNSES\#MDS). Este nuevo programa transforma la mirada sobre el trabajo y la asociatividad en la que se basaban los ante-

22 Se realizó a través de diferentes estrategias: Ley 26117 de Promoción de Microcrédito y la constitución de la Comisión Nacional de Promoción del Microcrédito (Conami) y el Programa Nacional de Microcrédito Padre Carlos Cajade.

${ }^{23}$ A través de resoluciones Res. MDS 456/16, 592/16 y 2055/16. 
riores (la cooperativa como unidad organizadora) para poner foco en el desarrollo de capacidades que permitan mejorar la propia empleabilidad y fomentar la «cultura del trabajo». "Hacemos Futuro» requiere como contraprestación por los ingresos percibidos (al que la resolución refiere como subsidio) una capacitación de carácter personal que implica la finalización de los estudios primarios y secundarios y/o la capacitación en oficios, que brindarán herramientas para la "autonomía económica» (op. cit.). Se focaliza en la formación individual de las personas beneficiarias, y no en la trayectoria laboral que se logró hasta el momento (dando por supuesto que la formación es condición suficiente para la inserción laboral). Además, se dejan explícitamente de lado todas las consideraciones en perspectiva de género que, con sus dificultades, intentaba garantizar el programa «Ellas Hacen» en los territorios. Esto último incluye no solamente formaciones, sino la pérdida de los espacios colectivos que favorecieron la organización, el fortalecimiento de una identidad como trabajadoras y empoderamiento como sujetas de derecho.

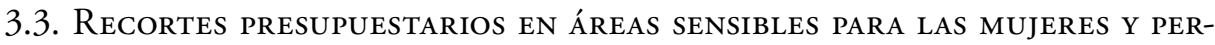 SONAS LGBT}

En las políticas fiscales se materializan las prioridades económicas de los gobiernos que permiten entender quiénes y con cuánto van a contribuir al sostenimiento de la economía y a quiénes va a otorgar el Gobierno bienes y/o servicios, es decir, cómo se configura el rol redistribuidor del Estado. Entendemos que las políticas fiscales como expresión de las políticas públicas no son neutrales a las relaciones de género, están atravesadas por estas y pueden tanto incrementar las desigualdades como desafiarlas. Analizar las políticas de gastos desde una perspectiva de género resulta clave para entender las cuestiones de equidad distributiva (Rodríguez Enríquez). El análisis presupuestario con perspectiva de género permite comprender en qué medida los presupuestos públicos tienden a garantizar derechos y a reducir las brechas y desigualdades de género, o en qué medida tienden a profundizar la discriminación. A la hora de identificar organismos y políticas relevantes para la igualdad de género, se debe tener presente que ellos pueden tener un impacto, tanto implícito como explícito, y pueden abordar tanto un tema específico como la cuestión de la igualdad de manera transversal. Es usual clasificar los gastos públicos con relación a la igualdad de género en tres categorías (Rodríguez Enríquez): el gasto etiquetado, los gastos para promover oportunidades en el empleo público y los gastos generales. A los efectos de este trabajo, proponemos analizar sucintamente el gasto desde una perspectiva de género que no se centre únicamente en gastos etiquetados como tales, ya que existen gastos con potencialidad en términos de equidad de género que pueden igualmente afectar positiva o negativamente la equidad (Rodríguez Enríquez). En este sentido, pueden serlos aquellos que se orientan a sectores de empleo con sobrerrepresentación de fuerza de trabajo femenina (como el trabajo en casas particulares), o subrrepresentación de fuerza de trabajo femenina, o determinadas políticas sociales enfocadas en los sectores más vulnerables donde las mujeres tienden a estar sobrerrepresentadas. 
El gasto etiquetado en el presupuesto es el gasto específicamente orientado a satisfacer derechos de las mujeres y personas LGBT. Particularmente, en el año 2018 el Gobierno ha avanzado tanto en la desagregación de información como en el reconocimiento de más partidas presupuestarias que pueden afectar las condiciones de vida en específico de las mujeres, aunque todavía la transparencia sobre esta información es insuficiente para poder analizar tanto los presupuestos como su ejecución. Es importante extender el análisis a otros programas y actividades que no están etiquetados, dado que la igualdad de género debería ser un objetivo transversal de todas las políticas.

Realizando un análisis general de las partidas que pueden tener una incidencia particularmente sensible en el acrecentamiento del trabajo doméstico y de cuidados no remunerado y en las condiciones laborales de las mujeres cis podemos observar que en varios sectores el gasto de la Administración Pública Nacional ha disminuido en porcentajes importantes. Cae el gasto público en sectores altamente feminizados en términos de empleo, como la salud (siete de cada 10 trabajadorxs del sector salud son mujeres), la educación y cultura (siete de cada 10 trabajadorxs del sector educación y cultura son mujeres) y ciencia y técnica $(60,2 \%$ del total de investigadores y becarios registrados en CVAr son mujeres). Además, son las mujeres las que, principalmente, se encargan de proveer y solucionar los problemas en torno a los servicios como la salud, la educación, así como también la provisión de agua, el alcantarillado y los servicios sanitarios en los hogares. El recorte presupuestario en estas áreas hace que las mujeres individual o comunitariamente sostengan estas tareas que el Estado deja de proveer. Disminuye también el presupuesto para vivienda y urbanismo, área sumamente sensible ante el déficit de vivienda y la titularidad de la propiedad en un país donde los hogares monomarentales crecen ostensiblemente. La contracara de estos recortes es el aumento a más del doble en los servicios de la deuda pública pagados por el Gobierno.

\begin{tabular}{lcc}
\hline \multicolumn{2}{l}{ TABLA 1. GASTOS DE LA APN, \% SOBRE EL GASTO TOTAL. ÍTEMS SELECCIONADOS } \\
\hline & AÑo 2015 & AÑo 2018 \\
\hline Salud & 3,9 & 3,6 \\
\hline Educación y Cultura & 6,9 & 5,8 \\
\hline Ciencia y Técnica & 1,5 & 1,1 \\
\hline Trabajo & 0,4 & 0,2 \\
\hline Vivienda y Urbanismo & 2,1 & 1,1 \\
\hline Agua Potable y Alcantarillado & 1,1 & 0,6 \\
\hline Servicio de la Deuda Pública & 7,7 & 16,8 \\
\hline
\end{tabular}

Fuente: elaboración propia en base a datos del Ministerio de Hacienda.

Al momento de analizar el presupuesto con gasto etiquetado, nos vemos ante una serie de dificultades. Si bien ante la Agenda 2030 proponen los cumplimientos internacionales que deben hacer los Estados en materia de transparencia de 
la información para conseguir los objetivos del desarrollo sostenible y la presión de la sociedad civil, se han dado algunos pasos para comenzar a implementar presupuestos y monitoreo de gastos con perspectiva de género. Ahora bien, nos enfrentamos a muchos avatares a la hora de poder encontrar la información desagregada para analizar las partidas presupuestarias y la ejecución efectiva de tales gastos. La información todavía se encuentra poco desagregada, los gastos específicos se encuentran dentro de grandes programas de gasto, lo cual no nos permite analizar de forma desagregada el período de estudio, salvo para algunos programas en concreto. Cabe destacar que el análisis aquí realizado amerita una profundización mayor en tanto contenidos de programas y metas físicas, este es sólo un análisis cuantitativo que mide la inversión destinada.

En el año 2018 la Dirección nacional de política fiscal y de ingresos presentó, en el marco de la presentación del Plan Nacional de Igualdad de Oportunidades y Derechos 2018-2020, la Mesa de diálogo «Hacia un presupuesto con perspectiva de género", una serie de programas destinados específicamente o con alta incidencia en las mujeres. Según la información provista por (ACIJ) y dicha mesa de diálogo, se pueden observar algunas de las políticas y programas que el Estado ha seleccionado como destinadas hacia las mujeres, esto es, con una perspectiva de género limitada, ya que no se consideran en su retórica otras identidades. En suma, analizando ese conjunto de asignaciones, el presupuesto representó en el 2016 un $2,29 \%$, en el 2017 un total de 2,81\% y en el 2018 un total de 3,6\% considerando el crédito vigente asignado.

Para el año 2019, el Estado avanzó en la producción de información y la asignación de etiquetas a políticas y programas con posible impacto positivo en las condiciones de vida de mujeres y personas LGBT. La clasificación la realiza entre programas con impacto directo en la sociedad y con impacto indirecto en la sociedad (acciones al interior de la Administración Pública Nacional). El presupuesto identificado con las temáticas de género asciende a $\$ 178432$ millones, lo que representa el $4,29 \%$ del gasto primario de la Administración Pública Nacional. Sin embargo, que el peso de estos programas ascienda a 4,29\% en el presupuesto del año 2019 no es que necesariamente se hayan destinado más recursos económicos, sino que actualmente se están considerando más políticas y programas dentro del análisis etiquetado que se pueden identificar. En este sentido, los cambios constantes de consideración de gasto etiquetado y la nominación de los programas hacen complejo analizar cómo afecta el delicado proceso inflacionario que devalúa el peso argentino y coarta las condiciones de vida de la población.

Una cuestión a notar es que gran parte del gasto seleccionado es destinado a sostener programas de transferencias de ingresos a la población que tiene una mayor dependencia, esto es, a las y los niños y las y los adultos mayores. Por ejemplo, es una constante que el mayor porcentaje de gasto destinado en el cuadro de referencia es para la Asignación Universal para la Protección social (asignación universal por hijo y asignación universal por embarazo), que en todos los casos acapara más del $60 \%$ del presupuesto en gasto sensible considerado. Si observamos los dos programas específicos destinados a la autonomía monetaria de las mujeres cis más vulnerables, Ellas Hacen/Hacemos Futuro y las Pensiones no Contributivas para madres de siete o más 
hijos ambos programas representan cada uno un $1 \%$ del total de gasto presupuestado. Más allá de que en términos del presupuesto etiquetado es el gasto más dinámico en cuanto a incrementos nominales a través de los años, como se especificó en el apartado "Deterioro de los ingresos en los programas de transferencias condicionadas", dada la creciente inflación estos montos no cubren las canastas básicas necesarias para superar la línea de pobreza y fueron seriamente deteriorados en términos reales.

Ahora bien, ambas partidas visibilizan la pobreza de ingresos de las mujeres y la necesidad de contar con un ingreso económico para el sostenimiento de ellas y sus dependientes, teniendo en cuenta que la tasa de desempleo en jóvenes es de más del $20 \%$ en Argentina.

\subsubsection{Cumplimiento de las obligaciones del Estado en torno a los derechos de las mujeres $y$ personas $L G B T$}

El Equipo Latinoamericano de Justicia y Género (ELA) ha observado que el acceso, permanencia y ascenso al mercado laboral en igualdad de condiciones y los derechos de las mujeres cis son un foco clave para superar la brecha salarial. En este sentido, la inversión asignada en el período de referencia es poco significativa, lo que difícilmente redunda en la dedicación necesaria para contribuir a la transformación de las barreras estructurales a la igualdad de oportunidades y derechos en el mundo del trabajo (ELA). Es preocupante la desidia con la que el Estado ha omitido su actuación en garantizar la igualdad de oportunidades y el acceso al trabajo para las personas travesti, trans, como así también las personas LGBT. Al tiempo, es preocupante que no se haya avanzado en absoluto en garantizar la aprobación y ejecución del cupo laboral travesti y trans en las provincias, como así también la ley de identidad de género y la efectiva protección social que necesita la población trans discriminada y vulnerada en sus condiciones de vida. Para poder avanzar en trastocar las condiciones estructurales que sostienen las desigualdades, y entre ellas un acceso equitativo al mundo del trabajo, es indispensable que se promueva una organización social del cuidado más justa teniendo en cuenta tanto la reorganización de la división sexual del trabajo como el reparto entre los distintos actores del cuidado. Estas políticas deberían abordar la necesaria universalidad de acceso a los tiempos para cuidar, el dinero para cuidar y la infraestructura de cuidado (ELA), sin que se trate de derechos derivados de la condición de empleo de las personas (ELA).

Con respecto a los programas sobre Salud Sexual y procreación responsable al mismo tiempo que el Programa de Educación Sexual Integral, la discusión sobre la interrupción legal del embarazo en el 2018 en el Congreso y en la sociedad fue central para poner en el tapete los derechos sexuales y reproductivos en Argentina. Ambos programas se incrementaron en un 50\% y un 369\% respectivamente, si bien la inflación para el año 2018 alcanzó un 47,6\% y en términos del presupuesto total representan menos del 0,01\% del presupuesto. Cabe destacar que en Argentina hay 700000 nacimientos por año, una adolescente tiene un hijo/a cada seis minutos $y$, por día, nacen siete bebés de niñas menores de 15 años. El 16\% proviene de adolescentes 
de entre 15 y 19 años (en algunas provincias equivale al 25\%) y más de 3000 son de niñas de 10 a 13 ańos. El 69\% de esas/os adolescentes no planearon ese embarazo.

Para el caso del programa referido a la Lucha Contra el SIDA y a Enfermedades de Transmisión Sexual e Infecto Contagiosas, si bien el presupuesto del 2018 al 2019 se ha mantenido constante en términos reales de acuerdo a la inflación (tuvo un incremento del 48,6\%), es denunciada por las personas que viven con $\mathrm{VIH} \mathrm{e}$ infecciones de transmisión sexual la falta de medicamentos necesarios para poder llevar adelante sus tratamientos. Durante todo el período, el Estado ha subejecutado el presupuesto en esta partida en un 31\%, 16\% y 31\% respectivamente para los años 2016, 2017 y 2018. Bajo la consigna \#SinMedicamentosNosMorimos, el Frente Nacional por la Salud de las personas con $\mathrm{VIH}^{24}$ ha venido denunciando el faltante de medicamentos. Para el año 2019, peligra la entrega de medicación a más de 15000 personas con VIH. Asimismo, se ha denunciado la entrega de medicación vencida o el cambio abrupto de medicación para pacientes que vienen llevando un tratamiento prolongado y que necesitan previsibilidad los tratamientos, ya que de otra forma los cambios repentinos ante la falta generan estragos en su salud.

Tanto si observamos el presupuesto en grandes ítems seleccionados por jurisdicción como salud, educación, trabajo como si tenemos en cuenta las partidas presupuestarias de gasto etiquetado con perspectiva de género, podemos concluir que tanto para el 2015 como para el 2018 de cualquier manera los servicios de la deuda pública, esto es, 7,7\% y 16,8\% del gasto total de la Administración Pública Nacional respectivamente, superaron con creces el gasto destinado a la protección social sensible para revertir las desigualdades de género.

\section{CONCLUSIONES}

El propósito de este trabajo fue posibilitar un acercamiento del panorama de algunas condiciones estructurales en las que se encuentran las mujeres cis y modestamente las personas LGBT en la economía argentina, y cómo han impactado sobre ellas las políticas de austeridad aplicadas durante la gestión del Gobierno que asumió en diciembre del 2015. A pesar de las continuidades estructurales que ha tenido el modo de desarrollo en Argentina en los últimos 40 años, la profundización del esquema basado en la explotación de recursos naturales y la valorización financiera durante la gestión de Cambiemos han impactado fuertemente sobre los cuerpos de las mujeres y las personas LGBT, lo cual desembocó en el recrudecimiento del programa de austeridad y endeudamiento. Este programa tuvo serios efectos en las condiciones de vida de mujeres y personas LGBT, que fueron los movimientos más dinámicos de resistencia pública a tal programa. Aunque no fue desarrollado en el presente trabajo, esto pudo observarse a través de la represión de los cuerpos-terri-

${ }^{24}$ Para más información ver el trabajo de fundación GEP https://fgep.org/es/ y https:// es-la.facebook.com/FrenteNacionalporlasaluddelaspersonasconVIH/. 
torios, tanto a partir de la oleada de conflictos socioambientales derivados de las luchas, encabezadas la mayoría de las veces por mujeres cis, para evitar el avance del capital sobre los territorios, como de los cuerpos-territorios en las calles, procurando una ofensiva ante el ajuste estructural y la avanzada conservadora, en los que también se incluyeron la represión sexual, el avance de la ideología de género y el incremento de la transfobia entre otras. No es menor en este sentido que el mayor actor de unidad y dinamismo de la conflictividad social hayan sido los feminismos con masivas manifestaciones en las calles.

Por otro lado, el impacto sobre los cuerpos de la redistribución de los recursos del Estado para subsidiar al capital financiero y especulativo en detrimento del sostenimiento de las políticas de protección social, de los ingresos salariales y no salariales. En este sentido, uno de los grandes objetivos del modelo de desarrollo de Cambiemos fue el aumento de la competitividad internacional vía abaratamiento de la mano de obra. Con este propósito se llevaron a cabo una serie de medidas que impactaron más negativamente sobre las mujeres y las personas LGBT que sobre los varones cis. La reforma previsional (encubierta) del 2016 y del 2017, los recortes presupuestarios en áreas sensibles al género y el cambio en la naturaleza de las políticas sociales son algunos de los ejemplos que analizamos en este trabajo.

Por último, es importante aclarar que no existen metodologías específicas sobre cómo analizar los impactos de las políticas de austeridad con el análisis transversal que aquí proponemos. Aunque reconocemos que aún hay mucho más por explorar, tratamos de aproximarnos a categorías/aristas para poder acercar un análisis posible ante el vacío teórico. 


\section{BIBLIOGRAFÍA}

ACIJ. Análisis presupuestario con perspectiva de género. Manual para activistas y organizaciones de la sociedad civil. ACIJ, 2019, https://acij.org.ar/wp-content/uploads/2019/05/Guia-Analisis-Presupuestario-Con-Perspectiva-de-Genero.pdf. Consultado el 3 de abril de 2020.

Águila, Nicolás. «Tendencias contrapuestas en la participación de las mujeres en el mercado laboral argentino: Un análisis desagregado del empleo femenino para el período 2003-2013». ASET, 2015, https://www.aset.org.ar/2015/ponencias/6_Aguila.pdf.

BADgetT, M.V. Lee, et al. «The Relationship between LGBT Inclusion and Economic Development: Macro-Level Evidence». World Development, vol. 120, agosto de 2019, pp. 1-14. Crossref, doi: https://doi.org/10.1016/j.worlddev.2019.03.011.

Benería, Lourdes, et al. Gender, Development, and Globalization: Economics as If All People Mattered. Routledge, Taylor \& Francis Group, 2016.

CAĞATAY, Nilüfer. «Gender Inequalities and International Trade: A Theoretical Reconsideration». Serie Seminarios y Talleres, 136. Montevideo, CIEDUR y Capítulo Latinoamericano de la Red Internacional de Género y Comercio (IGTN). 2005.

Cavallero, Luci y Gago, Verónica. Una lectura feminista de la deuda. Fundación Rosa Luxemburgo, 2019.

CEPA. Análisis de los impactos del aumento de precios de alimentos de la canasta básica sobre la Asignación Universal por Hijola a diciembre 2019. CEPA, 2019, https:/gallery.mailchimp.com/ e9c6f62a4dc825f6a9dab4e88/files/c32dfe67-ffba-4f62-bd6e-aba77aacbe02/2019.09.16_ Los_impactos_del_aumento_de_precios_de_alimentos_de_la_canasta_b\%C3\%A1sica_ sobre_la_AUH_CEPA.pdf.

Constantino, Agostina. «La extranjerización de la tierra en Argentina. Continuidades y cambios entre el macrismo y el kirchnerismo». Estudos internacionais: revista de relaçōes internacionais da PUC Minas, 5: 2 (2017), p. 103. Crossref, doi: https://doi.org/10.5752/P.2317773X.2017v5n2p103.

Costantino, Agostina y Camtamutto, Francisco J. «Modos de desarrollo y realización de derechos en América Latina», en Ansolabehere, Karina et al. (eds.), Entre el pesimismo y la esperanza: Los derechos humanos en América Latina. Metodología para su estudio y medición, FLACSO México, 2015, pp. 181-213.

Costantino, Agostina y Gamallo, Leandro. «Los conflictos socioambientales durante los gobiernos kirchneristas en Argentina», en Vázquez Valencia, Luis Daniel, De la democracia liberal a la soberania popular. Vol. 2: Articulación, representación y democracia en América Latina, CLACSO, 2015.

Costantino, Agostina, y Laterra, Patricia. «La teoría marxista de la dependencia desde una mirada feminista: un análisis sobre las leyes sobre aborto en el mundo». Cadernos Cemarx, 10 (2018). https://www.ifch.unicamp.br/, https://www.ifch.unicamp.br/ojs/index.php/cemarx/article/view/2943.

Duflo, Esther. «Women Empowerment and Economic Development». Journal of Economic Literature, 50: 4 (2012), pp. 1051-79. Crossref, doi: https://doi.org/10.1257/jel.50.4.1051.

ELA. Análisis del proyecto de presupuesto 2019 desde una perspectiva de género: avances y retrocesos para la igualdad. ELA, 2018. 
Elson, Diane. «International Trade and Gender Equality: Women as Achievers of Competitive Advantage and the Sources of Competitive Advantage». Departamento de Sociología, Universidad de Essex, Reino Unido. Documento preparado para el «International Symposium on Gender at the Heart of Globalization", realizado en París del 21-23 de marzo de 2007.

Enríquez, Corina Rodríguez y Marzonetto, Gabriela. «Organización social del cuidado y desigualdad: el déficit de políticas públicas de cuidado en Argentina». Revista Perspectivas de Politicas Públicas, 4: 8 (2015), pp. 105-34. http://revistas.unla.edu.ar/, https://doi.org/ doi:10.18294/rppp.2015.949.

Esquivel, Valeria, et al. Las Lógicas Del Cuidado Infantil: Entre Las Familias, El Estado y El Mercado. IDES, 2012. https://www.researchgate.net/, https://www.researchgate.net/publication/236943477_Las_logicas_del_cuidado_infantil_entre_las_familias_el_estado_y_ el_mercado.

FÉLIz, Mariano. «Neoextractivismo, neodesarrollismo y proceso de acumulación de capital. ¿¿Superando el ciclo stop-and-go? Argentina, 2003-2012». VII Jornadas de Sociología de la UNLP "Argentina en el escenario latinoamericano actual: debates desde las ciencias sociales», FAHCE UNLP, 2012.

Fontana, Marzia. Survey of research on gender and trade: insights, gaps and coverage. Institute of Development Studies, Universidad de Sussex. Documento presentado en «Gender in Global and Regional Trade Policies: Contrasting Views and New Research». CSGR, Universidad de Warwick, 5-7 de abril de 2006.

Floro, Maria. «Feminist Economist's Reflections on Economic Development: Theories and Policy Debates", en Nissanke, Machiko y Ocampo, José Antonio (eds.), The Palgrave Handbook of Development Economics. Critical Reflections on Globalisation and Development, Palgrave Macmillan, 2019, pp. 247-278.

Hopp, Malena. «De la promoción del trabajo cooperativo al salario social complementario. Transformaciones en la transferencia de ingresos por trabajo en la Argentina». Ciudadanias. Revista de Politicas Sociales Urbanas, 2 (2018). http://ciudadanias.untref.edu.ar/pdf/n2_ dossier_art5.pdf.

International Labour Organization y United Nations Development Programme. Trabajo decente y cuidado compartido: hacia una propuesta de parentalidad. 2013.

Kabeer, Naila. «Gender Equality and Women's Empowerment: A Critical Analysis of the Third Millennium Development Goal». Gender \& Development, 13: 1 (2005), pp. 13-24. Crossref, doi: https://doi.org/10.1080/13552070512331332273.

Laterra, Patricia, et al. Las politicas de «austeridad» en la Argentina y su impacto diferenciado en las mujeres, travestis y personas trans. CELS, 2018, https:/www.cels.org.ar/web/wp-content/ uploads/2018/04/20180405_Impacto_politicas_economicas_mujeres-2.pdf.

LupICA, Carina. Trabajo decente y corresponsabilidad de los cuidados en Argentina. OIT, 2010, https:// www.oitcinterfor.org/sites/default/files/file_publicacion/td_corresponsa.pdf.

Marini, Ruy Mauro. «La acumulación capitalista mundial y el subimperialismo». Cuadernos políticos, 12 (1977), p. 26.

Osorio, Jaime. Patrones exportadores en América Latina. UAM, 2010.

Poulantzas, Nicos. Poder politico y clases sociales en el Estado capitalista. Siglo XXI, 1969. 
RaZAVI, Shahra (ed.). «The Gendered Impact of Globalisation. Towards ‘Embedded Liberalism’?», en Razavo, Shahra (ed.), The Gendered Impact of Globalisation. Towards Embedded Liberalism?, Routledge, 2009, pp. 1-34.

Rodríguez Enríquez, Corina. La organización del cuidado de niños y niñas en Argentina y Uruguay. CEPAL, 2007. repositorio.cepal.org, https://repositorio.cepal.org//handle/11362/5813.

Rodríguez Enríquez, Corina. Gastos, tributos y equidad de género. Una introducción al estudio de la politica fiscal con perspectiva de género. Buenos Aires: Ciepp. Documento de trabajo 66, 2008.

Rodríguez Enríquez, Corina. Introducción a la Economía Feminista. 2017.

Rodríguez Enríquez, Corina y Pautassi, Laura. La organización social del cuidado de niños y niñas. Elementos para la construcción de una agenda de cuidados en Argentina. ELA, CIEPP y ADC, 2014.

SCARAno, Alejandra, et al. Mujeres argentinas Entre la organización por la conquista de derechos y la profundización de las inequidades económicas. CEPA, 2019. 
